\title{
Efficacy and Predictors for Biofeedback Therapeutic Outcome in Patients with Dyssynergic Defecation
}

\author{
Ting Yu, ${ }^{1}$ Xiaoxue Shen, ${ }^{1}$ Miaomiao Li, ${ }^{1,2}$ Meifeng Wang, ${ }^{1}$ and Lin Lin ${ }^{1}$ \\ ${ }^{1}$ Department of Gastroenterology, The First Affiliated Hospital of Nanjing Medical University, No. 300 of Guangzhou Road, \\ Nanjing, China \\ ${ }^{2}$ Department of Gastroenterology, Huaian First Hospital Affiliated to Nanjing Medical University, No. 6 of West Beijing Road, \\ Huaian, China \\ Correspondence should be addressed to Lin Lin; linlin9100@aliyun.com
}

Received 12 May 2017; Revised 20 July 2017; Accepted 1 August 2017; Published 29 August 2017

Academic Editor: Paul Enck

Copyright @ 2017 Ting Yu et al. This is an open access article distributed under the Creative Commons Attribution License, which permits unrestricted use, distribution, and reproduction in any medium, provided the original work is properly cited.

\begin{abstract}
Aim. To evaluate the short-term efficacy of biofeedback therapy (BFT) for dyssynergic defecation (DD) and to explore the predictors of the efficacy of BFT. Methods. Clinical symptoms, psychological state, and quality of life of patients before and after BFT were investigated. All patients underwent lifestyle survey and anorectal physiology tests before BFT. Improvement in symptom scores was considered proof of clinical efficacy of BFT. Thirty-eight factors that could influence the efficacy of BFT were studied. Univariate and multivariate analysis was conducted to identify the independent predictors. Results. Clinical symptoms, psychological state, and quality of life of DD patients improved significantly after BFT. Univariate analysis showed that efficacy of BFT was positively correlated to one of the 36-item Short-Form Health Survey terms, the physical role function $(r=0.289 ; P=0.025)$, and negatively correlated to the stool consistency $(r=-0.220 ; P=0.032)$, the depression scores $(r=-0.333 ; P=0.010)$, and the first rectal sensory threshold volume $(r=-0.297 ; P=0.022)$. Multivariate analysis showed depression score $(\beta=-0.271 ; P=0.032)$ and first rectal sensory threshold volume $(\beta=-0.325 ; P=0.013)$ to be independent predictors of BFT efficacy. Conclusion. BFT improves the clinical symptoms of DD patients. Depression state and elevated first rectal sensory threshold volume were independent predictors of poor outcome with BFT.
\end{abstract}

\section{Introduction}

Chronic constipation (CC) is diagnosed when there is at least a 6-month history of symptoms such as infrequent bowel movement, reduced stool volume, hard stools, and excessive straining at defecation [1]. Treatment can be very difficult. The median prevalence is $16 \%$ in the US and is as high as $33.5 \%$ in adults aged $60-101$ years [2]. The overall prevalence in Chinese adults is $16 \%-20 \%$ [3].

Primary constipation consists of several overlapping subtypes, among which dyssynergic defecation (DD) is relatively common $[4,5]$. Patients with DD have symptoms of obstructive defecation, such as severe straining during defecation and a sensation of a "blockage" and of incomplete evacuation. The physiological mechanisms of DD include inability to coordinate abdominal, rectoanal, and pelvic floor muscles during defecation because of causes such as inadequate rectal and/or abdominal propulsive force, impaired anal relaxation (i.e., $<20 \%$ relaxation of basal resting pressure), or increased anal outlet resistance as a result of paradoxical external anal sphincter or puborectalis contraction [6, 7]. Pharmacological therapies that are usually effective in CC, such as bulking agents, osmotic laxatives, stimulant laxatives, and stool softeners [8], are often ineffective in DD patients [9].

Biofeedback therapy (BFT), which is based on behavior modification [10], can be used to train DD patients to defecate effectively. Patients are taught to brace the abdominal wall muscles and relax the pelvic floor muscles during defecation, and efforts are also made to modify sensory perception in the rectum [11]. The first application of BFT for treatment of CC due to DD was in 1987 [12]. Since then, a number of controlled studies have shown that BFT can be more effective 
TABLE 1: Scoring system for symptoms of DD.

\begin{tabular}{|c|c|c|c|c|c|c|}
\hline Grading/score & $\begin{array}{c}\text { Defecation } \\
\text { interval (days) }\end{array}$ & Straining & $\begin{array}{c}\text { Sensation of } \\
\text { incomplete evacuation }\end{array}$ & Sensation of blockage & Painful defecation & $\begin{array}{c}\text { Stool } \\
\text { consistency }\end{array}$ \\
\hline 0 & $1-2$ & None & None & None & None & BSS: $4-7$ \\
\hline 1 & 3 & Occurs occasionally & Occurs occasionally & Occurs occasionally & Occurs occasionally & BSS: 3 \\
\hline 2 & $4-5$ & $\begin{array}{c}\text { Occurs during }>25 \% \\
\text { of defecations }\end{array}$ & $\begin{array}{l}\text { Occurs during }>25 \% \\
\text { of defecations }\end{array}$ & $\begin{array}{l}\text { Occurs during }>25 \% \\
\text { of defecations }\end{array}$ & $\begin{array}{c}\text { Occurs during }>25 \% \\
\text { of defecations }\end{array}$ & BSS: 2 \\
\hline 3 & $>5$ & $\begin{array}{l}\text { Occurs during }>50 \% \\
\text { of defecations }\end{array}$ & $\begin{array}{l}\text { Occurs during }>50 \% \\
\text { of defecations }\end{array}$ & $\begin{array}{l}\text { Occurs during }>50 \% \\
\text { of defecations }\end{array}$ & $\begin{array}{l}\text { Occurs during }>50 \% \\
\text { of defecations }\end{array}$ & BSS: 1 \\
\hline
\end{tabular}

$\mathrm{DD}=$ dyssynergic defecation; BSS = Bristol stool scale.

than laxatives, muscle relaxants, and placebo, with benefits lasting for at least 12 months [13-15]. Based on these findings, BFT has been recognized as the most effective treatment for DD for several years $[16,17]$. However, symptomatic improvement after BFT has varied widely between studies, ranging from $44 \%$ to $100 \%$ [18]. Few data are available regarding the factors predictive of success of BFT [19]. In our experience, we have seen that anorectal physiology, psychological state, quality of life, and lifestyle factors can all influence the efficacy of BFT.

The aim of this study was to investigate the short-term efficacy of BFT and to identify the clinical and physiological factors that predict success or failure following BFT in Chinese patients.

\section{Material and Methods}

2.1. Patients. In this retrospective study, all adult patients diagnosed with CC due to DD at the Department of Gastroenterology of the First Affiliated Hospital of Nanjing Medical University, between January 1, 2012, and October 30, 2015, were eligible for inclusion. CC was diagnosed if the patient had at least two of the following constipation symptoms for $>6$ months: (1) infrequent stools (<3 bowel movements/ week); (2) hard or lumpy stools (Bristol stool form scale score of 1-2) [20]; (3) straining at stool; (4) sensation of incomplete evacuation after bowel movement; or (5) sensation of anorectal blockage [21]. The presence of DD was determined using high-resolution anorectal manometry (HR-ARM) and rectal balloon expulsion test. Patients presented with inappropriate contraction or inadequate propulsive forces in HR-ARM and prolonged balloon expulsion time were considered to have DD. None of the patients had responded to standard management of constipation (e.g., increased dietary fiber and fluid intake or laxatives). Patients were excluded from the study if they (1) were $<18$ years in age, (2) had structural bowel disease or history of abdominal surgery, (3) had mental illness, (4) had recently received psychotropic drugs [22], (5) were pregnant, or (6) had not completed a full course of BFT (4 sessions).

This study was approved by the Ethics Committee of the First Affiliated Hospital of Nanjing Medical University (2016-SRFA-064).

2.2. Constipation Severity. A questionnaire (Table 1) adapted from the one developed by the Cleveland Clinic was used to assess defecatory symptoms [23] such as frequency of spontaneous bowel movements, stool consistency, straining during defecation, sensation of incomplete evacuation, sensation of blockage, and painful defecation. The latter four are deemed to be relatively specific for DD and were scored on a scale of 0 to 3 , where $0=$ never occurred, $1=$ occurred occasionally, $2=$ occurred during $25 \%$ of defecations, and $3=$ occurred during $50 \%$ of defecations. The frequency of spontaneous bowel movements was scored as $0=$ defecation interval 1-2 days, $1=$ defecation interval 3 days, $2=$ defecation interval $4-5$ days, and $3=$ defecation interval $>5$ days. Stool consistency was evaluated according to the Bristol stool scale (a 7-point scale, ranging from $1=$ separate hard lumps like nuts to 7 =watery) [20]; in this study, the scores were allotted as follows: Bristol type $4-7=$ score 0 , Bristol type $3=$ score 1 , Bristol type $2=$ score 2 , and Bristol type $1=$ score 3 .

2.3. Assessment of Psychological State and Quality of Life. Zung's Self-Rating Anxiety Scale (SAS) [24] and Self-Rating Depression Scale (SDS) [25] were used to evaluate the levels of anxiety and depression. In Chinese populations, $S A S \geq 50$ and $S D S \geq 53$ represent diagnosable anxiety and depression [26]. The 36-item Short-Form Health Survey (SF-36) was used to evaluate quality of life [27]. The SF-36 consists of eight sections: vitality, physical functioning, bodily pain, general health perceptions, physical role functioning, emotional role functioning, social role functioning, and mental health. The scores in each section are the weighted sums of the scores for each question in that section. The scale is directly transformed into a 0-100 scale on the assumption that each question carries equal weight. The higher the score, the better the patient's quality of life.

2.4. Lifestyle Survey. Information on physical activity, work pressure, and sleep quality were obtained from questionnaires filled in at first contact with the patient. Physical activity was assessed by one question on the frequency of exercise of at least 30 minutes per session during the past week; the possible responses were "often," "sometimes," "seldom," and "never." Work pressure was graded as "low," "normal," high," and "very high." Sleep quality was assessed by the Pittsburgh Sleep Quality Index (PSQI) questionnaire [28]. The PSQI assesses seven components of sleep: the quality, latency, duration, and efficiency of sleep, sleep disturbances, use of sleeping medication, and daytime dysfunction. Each 
component is scored from 0 to 3 , and the seven component scores are summed to gain a global score. In Chinese populations, a PSQI global score $>7$ indicates poor sleep quality [29].

There were six questions on the frequency and/or volume of consumption of certain food items. Volume of intake was graded as "low," "normal," "high," or "very high," and frequency of consumption as "often," "sometimes," "seldom," or "never." Thus, we recorded the frequency and volume of consumption of vegetables (seldom, 250$<500 \mathrm{~g} / \mathrm{d}, 500-1000 \mathrm{~g} / \mathrm{d}$, and $>1000 \mathrm{~g} / \mathrm{d}$ ); fruits (seldom, $100-$ $200 \mathrm{~g} / \mathrm{d}, 200-500 \mathrm{~g} / \mathrm{d}$, and $>500 \mathrm{~g} / \mathrm{d})$; and water $(<500 \mathrm{~mL} / \mathrm{d}$, 500-1000 mL/d, >1000 mL/d). Predilection for a high-fat diet was also recorded (yes/no).

2.5. Rectal Balloon Expulsion Test. The time required for subjects to expel a rectal balloon filled with $50 \mathrm{~mL}$ of warm water while seated in privacy on a commode was measured. The balloon was removed if the subject was not able to expel the balloon within 1 minute $[30,31]$.

2.6. Colonic Transit Study. Colonic transit was assessed using radiopaque marker techniques. In brief, the patient ingested a single capsule containing 24 cylindrical radiopaque markers of $2 \mathrm{~mm}$ diameter and $6 \mathrm{~mm}$ length on day 1 . A supine radiograph of the abdomen was obtained on day 3 (i.e., 72 hours later) to assess the number and distribution of the markers in the colon; patients were deemed positive for delayed colonic transit if there were $>4$ markers distributed throughout the colon $[32,33]$.

2.7. High-Resolution Anorectal Manometry. A novel solidstate HR-ARM device (Manoscan AR 360; Given Imaging, Yokneam, Israel) with 12 sensors was used for anorectal manometry. The procedure was performed after defecation. The patient was placed in the left lateral decubitus position, with the hips flexed to $90^{\circ}$. The rectal balloon, with the attached catheter, was placed $3 \mathrm{~cm}$ proximal to the upper part of the anal sphincter. Measurements were made in the following order: resting anal and rectal pressure (20-30 seconds), pressure during squeeze (best of three attempts, with a maximum duration of 20-30 seconds per attempt), and pressure during bearing down as in defecation (best of three attempts, with 20-30 seconds per attempt) [34]. Rectal sensation was simultaneously evaluated; for this, the rectal balloon was progressively distended in $10 \mathrm{~mL}$ increments from $0 \mathrm{~mL}$ to $50 \mathrm{~mL}$, and threshold volumes for first sensation, urgency, and maximum discomfort were recorded.

Four phenotypes of DD have been recognized based on HR-ARM: type I dyssynergia, in which there is an adequate increase $(\geq 40 \mathrm{mmHg}$ ) in rectal pressure, accompanied by a paradoxical simultaneous increase in anal pressure; type II dyssynergia, in which there is an inadequate increase $(<40 \mathrm{mmHg})$ in rectal pressure (poor propulsive force), accompanied by a paradoxical increase in anal pressure; type III dyssynergia, in which there is an adequate increase $(\geq 40 \mathrm{mmHg}$ ) in rectal pressure, accompanied by failure of reduction in anal pressure (to $\leq 20 \%$ of baseline pressure); and type IV dyssynergia, in which there is an inadequate increase $(<40 \mathrm{mmHg})$ in rectal pressure (poor propulsive force), accompanied by failure of reduction in anal pressure (to $\leq 20 \%$ of baseline pressure) [1].

2.8. Biofeedback Training. The Polygraf ID 8 (Medtronic Ltd, Denmark) was used for biofeedback training. Patients received a 1-hour biofeedback training once every other day for the first 2 weeks, and 2-3 times per week thereafter. For the training session, the patient was asked to lie on the right side, and a single manometry catheter and anal electrode were inserted into the patient's anorectal canal at the sphincter. The catheter and the electrode were connected to the Polygraf ID, which displayed the data collected in the anorectal canal in a simple graphical format. The biofeedback application displayed a column, which the patient navigated using the pelvic floor muscles. By contracting and relaxing the pelvic floor muscles, the patient could move the signal level indicator up and down. The patient was instructed to try and keep the signal level within the limits of the column, while maintaining awareness of the changes in the pelvic floor muscle activity. They could thus learn to modulate the activity of the anorectal muscles [35]. During the training period, patients were required to practice at home, using the squeezing and relaxing maneuvers for 20 minutes at a time, 2-3 times/week. At the conclusion of biofeedback training, all patients were told that their pushing efforts had improved; this ensured that patients would be motivated to return for a follow-up and have positive expectations during the follow-up assessments.

2.9. Evaluation of Biofeedback Treatment Efficacy. Treatment efficacy was assessed at the completion of the BFT session. Treatment efficacy was expressed as a ratio, that is, the difference between the pretraining and posttraining constipation severity scores divided by the pretraining score, and graded as "very efficacious" (score $>0.05$ ), "efficacious" (score 0.250.50 ), or "not efficacious" (score $<0.25$ ).

2.10. Statistical Analysis. All data were analyzed using SPSS version 20.0 (IBM Corp., Armonk, NY, USA). Continuous variables were expressed as means \pm standard deviation or medians (range), and categorical variables as relative frequencies. Student's $t$-test or the Mann-Whitney $U$ test was used to compare continuous variables, and the chi-square test or Fisher's exact test for categorical variables. Univariate and multivariate analysis was used to identify the predictors of BFT efficacy. $P<0.05$ was considered statistically significant.

\section{Results}

The data of 171 patients (69 men and 102 women; mean age, $54.0 \pm 23.3$ years) were analyzed.

3.1. Baseline Clinical Symptoms, Psychological State, and Quality of Life. The mean disease duration was $6.5 \pm 2.5$ years. In this study population, $74.9 \%$ (128/171) patients had not had spontaneous bowel movements over the past 2 years. In all, 93.0\% (159/171) patients had history of longterm use of stimulant laxatives. The mean defecation interval 
TABLE 2: Symptom scores before and after BFT.

\begin{tabular}{lccc}
\hline Clinical symptoms & Before BFT & After BFT & $P$ \\
\hline Defecation interval (days) & $1.95 \pm 1.20$ & $1.20 \pm 0.91$ & 0.039 \\
Straining & $2.75 \pm 1.63$ & $1.60 \pm 1.15$ & 0.042 \\
Sensation of incomplete & $2.50 \pm 1.35$ & $1.62 \pm 1.15$ & 0.048 \\
evacuation & $1.82 \pm 1.40$ & $0.95 \pm 1.07$ & 0.021 \\
Sensation of blockage & $1.20 \pm 0.90$ & $1.17 \pm 074$ & 0.109 \\
Painful defecation & $1.82 \pm 1.20$ & $0.96 \pm 1.13$ & 0.034 \\
Stool consistency & $12.36 \pm 6.00$ & $7.61 \pm 4.52$ & 0.011 \\
Total &
\end{tabular}

Data are expressed as mean \pm standard deviation. $B F T=$ biofeedback therapy.

TABLE 3: SAS and SDS scores before and after BFT.

\begin{tabular}{lccc}
\hline & Before BFT & After BFT & $P$ \\
\hline SAS & $40.0 \pm 15.5$ & $33.5 \pm 10.9$ & 0.004 \\
SDS & $50.1 \pm 13.5$ & $46.0 \pm 13.5$ & 0.023 \\
\hline
\end{tabular}

Data are expressed as mean \pm standard deviation. SAS $=$ Zung's SelfRating Anxiety Scale; SDS =Zung's Self-Rating Depression Scale; $\mathrm{BFT}=$ biofeedback therapy.

was $1.95 \pm 1.20$ days, and the mean stool consistency score was $1.82 \pm 1.20$. Almost all patients had complaints of straining during bowel movement, sensation of incomplete defecation, sensation of blockage, or pain during defecation. Table 2 shows the defecatory symptom scores.

The anxiety and depression scores were $40.0 \pm 15.5$ and $50.1 \pm 13.5$, respectively, which were significantly higher than the Chinese norms $(33.80 \pm 5.90$ and $41.88 \pm 10.57$, resp.; Table 3) [26]; on the basis of these scores, $22.2 \%$ $(38 / 171)$ and $33.9 \%(62 / 171)$ of the patients had anxiety and depression, respectively.

Table 4 shows the scores of the DD patients in the different sections of the SF-36. All scores were significantly lower than the Chinese norms [36].

3.2. Baseline Lifestyle Factors. Table 5 shows the scores for physical activity, work pressure, sleep quality, and diet habits of the DD patients before BFT.

3.3. Baseline Anorectal Physiology. In this study, $48.5 \%$ $(83 / 171)$ patients presented with prolonged colonic transit time. The mean values for the manometric parameters were as follows: anal resting pressure $82.5 \pm 16.0 \mathrm{mmHg}$, maximum squeeze pressure $208.3 \pm 41.5 \mathrm{mmHg}$, rectal defecation pressure $38.9 \pm 8.6 \mathrm{mmHg}$, intrarectal pressure $88.9 \pm 15.3 \mathrm{mmHg}$, and rectoanal pressure differential $-42.0 \pm 8.5 \mathrm{mmHg}$, and threshold for the first sensation $60.0 \mathrm{~mL}$ (range, 20.0-220.0 mL), urgency $100.0 \mathrm{~mL}$ (range, 40.0-350.0 mL), and maximum discomfort $150.0 \mathrm{~mL}$ (range, 80.0-350.0 mL). According to the HR-ARM results, $82 / 171$ (48.0\%), 51/171 (29.8\%), 30/171 (17.5\%), and 8/171 (4.7\%) patients were classified as type I, type II, type III, and type IV DD, respectively.
TABLE 4: Scores for different quality of life indicators before and after BFT.

\begin{tabular}{lccc}
\hline Quality of life indicator & Before BFT & After BFT & $P$ \\
\hline General health perception & $41.3 \pm 19.0$ & $63.4 \pm 19.2$ & $<0.001$ \\
Physical functioning & $84.0 \pm 42.8$ & $88.5 \pm 39.2$ & 0.045 \\
Physical role functioning & $60.5 \pm 34.9$ & $72.6 \pm 39.0$ & 0.033 \\
Emotional role functioning & $63.8 \pm 32.0$ & $75.4 \pm 37.3$ & 0.038 \\
Social role functioning & $74.0 \pm 37.7$ & $80.1 \pm 37.5$ & 0.087 \\
Bodily pain & $75.0 \pm 40.0$ & $86.3 \pm 36.9$ & 0.029 \\
Vitality & $62.1 \pm 30.5$ & $70.8 \pm 23.0$ & 0.040 \\
Mental health & $63.2 \pm 23.6$ & $65.9 \pm 21.0$ & 0.049 \\
\hline
\end{tabular}

Data are expressed as mean \pm standard deviation. $B F T=$ biofeedback therapy.

TABle 5: Frequency table of lifestyle characteristics.

\begin{tabular}{lccc}
\hline Characteristic & $\begin{array}{c}\text { Frequency } \\
(n)\end{array}$ & Characteristic & $\begin{array}{c}\text { Frequency } \\
(n)\end{array}$ \\
\hline Physical activity & \multicolumn{3}{c}{ Fruit intake } \\
$\quad$ Often & 41 & Seldom & 11 \\
$\quad$ Sometimes & 67 & $100-200 \mathrm{~g} / \mathrm{d}$ & 90 \\
Seldom & 57 & $200-500 \mathrm{~g} / \mathrm{d}$ & 60 \\
$\quad$ Never & 6 & $>500 \mathrm{~g} / \mathrm{d}$ & 10 \\
Work pressure & & Water intake & \\
Low & 106 & $<500 \mathrm{~mL} / \mathrm{d}$ & 53 \\
Normal & 30 & $500-1000 \mathrm{~mL} / \mathrm{d}$ & 100 \\
High & 26 & $>1000 \mathrm{~mL} / \mathrm{d}$ & 18 \\
$\quad$ Very high & 9 & High-fat diet & \\
Poor sleep & & predilection & \\
quality & & Yes & 57 \\
No & 118 & No & 114 \\
Yes & 53 & & \\
Vegetable intake & & & \\
Seldom & 19 & & \\
$250-<500 \mathrm{~g} / \mathrm{d}$ & 44 & & \\
$500-1000 \mathrm{~g} / \mathrm{d}$ & 67 & & \\
$>1000 \mathrm{~g} / \mathrm{d}$ & 41 & & \\
\hline
\end{tabular}

3.4. Biofeedback Treatment Efficacy. Patients in this study received $10.0 \pm 3.5$ sessions of BFT. Treatment was assessed as "very efficacious" in $72.5 \%(124 / 171)$ patients, as "efficacious" in $8.2 \%(14 / 171)$ patients, and as "not efficacious" in $19.3 \%$ (33/171) patients; thus, the total efficacy was $80.7 \%$ (Table 6).

There was a very significant decrease in the total and subscale scores of bowel symptoms (defecation interval, straining at defecation, sensation of incomplete evacuation/ blockage, and stool consistency; Table 2).

Anxiety and depression was markedly improved, with significant decrease in the scores of SAS and SDS after the BFT (Table 3). In the SF-36, the scores for general health perception, physical functioning, and bodily pain 
TABLE 6: Clinical efficacy of BFT.

\begin{tabular}{lccc}
\hline Clinical efficacy & $n$ & Proportion (\%) & Grading of efficacy (\%) \\
\hline$\geq 75 \%$ & 73 & $42.7 \%$ & Very efficacious $(72.5 \%)$ \\
$50 \%-75 \%$ & 51 & $29.8 \%$ & \\
$25 \%-50 \%$ & 14 & $8.2 \%$ & Efficacious $(8.2 \%)$ \\
$\leq 25 \%$ & 33 & $19.3 \%$ & Not efficacious $(19.3 \%)$ \\
\hline
\end{tabular}

$\mathrm{BFT}=$ biofeedback therapy.

were increased significantly, indicating improvement in quality of life (Table 4).

3.5. Predictors of Outcome of BFT. Tables 7 and 8 show the association between the efficacy of BFT and psychological state, quality of life, lifestyle factors, and anorectal physiology. Univariate analysis showed that BFT efficacy was positively correlated to the score for physical role function $(r=0.289 ; P=0.025)$ and negatively correlated to the stool consistency score $(r=-0.220 ; P=0.032)$, the depression score $(r=-0.333 ; P=0.010)$, and the first sensory threshold volume $(r=-0.297 ; P=0.022$; Table 7$)$. Multivariate analysis showed that depression score $(\beta=-0.271$; $P=0.032)$ and the first sensory threshold volume $(\beta=$ $-0.325 ; P=0.013)$ were independent predictors of BFT efficacy (Table 8).

\section{Discussion}

In this study, we evaluated the efficacy of BFT in DD and attempted to identify the factors that could predict the success of BFT. We found that BFT could improve the clinical symptoms of patients with DD. The psychological state and the rectal first sensory threshold pressure were independent predictors of BFT outcome.

The prevalence of anxiety and depression in DD patients was much higher than the rates in the general population. These findings are consistent with previous literature that has documented a positive association-though not a causal relationship-between certain psychological disorders and DD $[37,38]$. We found that DD patients also have lower quality of life than the general population. This is not surprising, as the symptoms of constipation and psychological disorders can both disrupt daily living.

DD patients in our study frequently experienced excessive straining at defecation and a sensation of incomplete evacuation, with the average scores of $>2$ indicating that symptoms occurred during at least $25 \%$ of defecations. Prolonged colonic transit time was seen in $49.2 \%$ of DD patients. Significant overlap (10\%-60\%) between slow-transit constipation and DD as well as between slow-transit constipation and constipation-predominant irritable bowel syndrome has been described previously $[39,40]$, which suggests that a proportion of patients with constipation may have colonic motor and/or sensory dysfunction and coexisting anorectal sensorimotor dysfunction. In our study population, type I dyssynergia was seen in $48.6 \%$, type II dyssynergia in $28.4 \%$, type III dyssynergia in $20.8 \%$, and type IV dyssynergia in $2.1 \%$ of the patients. These rates are consistent with
TABLE 7: Univariate analysis of predictors of outcome of BFT.

\begin{tabular}{|c|c|c|}
\hline Variables & $r$ & $P$ \\
\hline \multicolumn{3}{|l|}{ General information } \\
\hline Age & -0.095 & 0.440 \\
\hline Gender & -0.112 & 0.202 \\
\hline Constipation duration & 0.115 & 0.197 \\
\hline \multicolumn{3}{|l|}{ Symptoms } \\
\hline Defecation interval & -0.062 & 0.683 \\
\hline Straining & -0.121 & 0.149 \\
\hline Sensation of incomplete evacuation & -0.092 & 0.450 \\
\hline Sensation of blockage & -0.145 & 0.106 \\
\hline Painful defecation & -0.040 & 0.849 \\
\hline Stool consistency & -0.220 & 0.032 \\
\hline \multicolumn{3}{|l|}{ Psychological status } \\
\hline SAS & -0.184 & 0.093 \\
\hline SDS & -0.333 & 0.010 \\
\hline \multicolumn{3}{|l|}{ Quality of life indicators } \\
\hline General health perception & 0.135 & 0.116 \\
\hline Physical functioning & 0.112 & 0.202 \\
\hline Physical role function & 0.289 & 0.025 \\
\hline Emotional role functioning & 0.120 & 0.207 \\
\hline Social role functioning & 0.153 & 0.104 \\
\hline Bodily pain & 0.046 & 0.751 \\
\hline Vitality & 0.196 & 0.084 \\
\hline Mental health & 0.205 & 0.057 \\
\hline \multicolumn{3}{|l|}{ Lifestyle } \\
\hline Physical activity & -0.079 & 0.666 \\
\hline Work pressure & -0.089 & 0.490 \\
\hline Poor sleep quality & -0.078 & 0.666 \\
\hline Vegetable intake & 0.145 & 0.106 \\
\hline Fruit intake & -0.062 & 0.683 \\
\hline Water intake & -0.095 & 0.468 \\
\hline High-fat diet predilection & 0.017 & 0.800 \\
\hline \multicolumn{3}{|l|}{ Anorectal physiology } \\
\hline BET time & -0.188 & 0.091 \\
\hline CTT & -0.062 & 0.711 \\
\hline \multicolumn{3}{|l|}{ HR-ARM } \\
\hline Anal resting pressure & 0.066 & 0.705 \\
\hline Maximum squeeze pressure & -0.030 & 0.761 \\
\hline Rectal defecation pressure & 0.082 & 0.650 \\
\hline Intrarectal pressure & 0.044 & 0.795 \\
\hline Rectoanal pressure differential & 0.197 & 0.090 \\
\hline First sensation volume & -0.297 & 0.022 \\
\hline Urgency volume & -0.178 & 0.091 \\
\hline Maximum discomfort volume & -0.074 & 0.700 \\
\hline DD subtype & -0.099 & 0.365 \\
\hline
\end{tabular}

BFT $=$ biofeedback therapy; SAS = Zung's Self-Rating Anxiety Scale; SDS = Zung's Self-Rating Depression Scale; BET = balloon expulsion test; $\mathrm{CTT}=$ colonic transit time.

previous studies $[6,41]$. The pathogenic mechanisms are different for the different subtypes of DD, and the response to BFT may vary greatly between subtypes. 
TABLE 8: Multiple linear regression analysis of predictors of BFT outcome.

\begin{tabular}{lccc}
\hline Variables & $\beta$ coefficient & $95 \%$ CI & $P$ \\
\hline Stool consistency & -0.110 & -0.213 to -0.032 & 0.176 \\
SDS & -0.271 & -0.506 to -0.036 & 0.032 \\
Physical role function & 0.112 & 0.204 to 0.020 & 0.172 \\
First sensation volume & -0.325 & -0.534 to -0.012 & 0.013 \\
\hline
\end{tabular}

BFT = biofeedback therapy; SDS = Zung's Self-Rating.

Recent controlled studies have shown that BFT is an effective treatment for pelvic floor dyssynergia [15, 42, 43]; BFT was found to be superior to laxatives, with improvement being maintained over a long-term follow-up. The superior efficacy of BFT was also demonstrated by Wang et al. [44] in their study of 50 CC patients. Seventy percent of their patients felt that BFT was helpful, and $62.5 \%$ were improved. Clinical manifestations such as straining, abdominal pain, and bloating were relieved, and the use of oral laxative decreased after BFT; frequency of spontaneous bowel movement and psychological state were also improved significantly after BFT. In our study, at the end of training, there was significant decrease in total and subscale scores of clinical symptoms, including frequency of spontaneous bowel movement, straining at defecation, sensation of incomplete evacuation, sensation of blockage, and stool consistency, suggesting that BFT was an effective behavioral treatment for DD. The emotional centers in the brain can affect motility and sensation in the gut, acting mainly via the hypothalamic-hypophyseal axis and brain-gut axis. Studies have shown that depression increases pelvic floor muscle tension and reduces rectal sensitivity $[45,46]$. Mild depression can be relieved to some extent by psychological counseling and by explanation of the symptoms. Both of these approaches are components of BFT, and therefore, BFT can improve the symptoms of both constipation and depression and help improve the overall quality of life of DD patients.

In our study, a harder stool was predictive of a substantial improvement in defecation symptoms after BFT. This finding is not unexpected because hard stool is a common feature of DD [1] and because BFT is known to improve dyssynergia and allow more efficient stool evacuation. Shim et al. studied 102 patients with CC and reported similar findings [47].

The SDS score was another predictor of BFT efficacy. Many patients with chronic diseases have concurrent depression. Depression is associated with poor treatment compliance, and some researchers consider that this may be an important factor for the failure of BFT in some patients [48-50]. In addition, patients with depression have autonomic nervous dysfunction; low vagal tone can result in decreased gastrointestinal motility [51]. However, Ding et al. have demonstrated that BFT has no effect on autonomic nervous function [35].

In our study, the only physiological parameter predictive of substantial improvement in defecation after BFT was the rectal first sensory threshold volume, an elevated value being related to poorer outcome with BFT. There could be several mechanisms for this. Normal rectal sensory function is essential for normal defecation. Patients with rectal hyposensitivity have elevated sensory thresholds, with resulting rectal dysfunction. Fecal retention in the rectum resulting from decreased desire to defecate leads to absorption of moisture from the stool, making it dry and hard. In addition, Schouten et al. have shown that rectal hyposensitivity patients have lower rectal contractility in response to rectal dilatation than control patients [52]. Decreased colonic motility could be another reason. Some rectal hyposensitivity patients have a primary decrease in colonic motility. Chronic dilatation of the rectum in these patients can cause a secondary decrease in proximal colonic motility (the rectum-colon reflex) [53]. Although there are studies proving the efficacy of BFT in slow-transit constipation, the findings are still debated $[11,54]$. Currently, there is no effective therapy available for rectal hyposensitivity; the options include sensory training, neural regulation, and surgery.

The results of this study may have been affected by some limitations. First, there is no uniform criterion for the curative effect of BFT on DD. We use the valid score that equals the decreasing index between pretraining and posttraining constipation severity scores divided by pretraining score to assess the efficacy. The constipation severity score used in our study was made up of the duplicate entries of the Cleveland Clinic Constipation Score and Rome III criteria. However, we have not test the reliability and validity of the questionnaire. This questionnaire may not reflect the constipation symptoms of the patient accurately. Second, BFT efficacy was assessed at the completion of the BFT session. We have not assessed the long-term outcome of BFT. Also, we do not know the predictors for long-term efficacy of BFT.

\section{Conclusion}

BFT improves the clinical symptoms of DD patients. High SDS score and elevated first rectal sensory threshold volume are independent predictors of poor outcome with BFT. Treatment for depression and rectal hyposensitivity could optimize the effects of BFT in DD patients.

\section{Abbreviations}

BFT: $\quad$ Biofeedback therapy

DD: Dyssynergic defecation

CC: $\quad$ Chronic constipation

HR-ARM: High-resolution anorectal manometry

SAS: $\quad$ Zung's Self-Rating Anxiety Scale

SDS: $\quad$ Zung's Self-Rating Depression Scale

SF-36: 36-item Short-Form Health Survey

PSQI: $\quad$ Pittsburgh Sleep Quality Index.

\section{Disclosure}

The abstract has been presented in the journal of Gastroenterology in volume 152, issue 5, supplement 1, page S755. 


\section{Conflicts of Interest}

No conflicts of interest were declared.

\section{Authors' Contributions}

Ting Yu, Xiaoxue Shen, and Miaomiao Li contributed equally to this work.

\section{Acknowledgments}

The authors thank the staff of the Pancreas Center of the First Affiliated Hospital of Nanjing Medical University for providing statistical support for this study. This work was supported by the National Natural Science Foundation of China (NSFC 81670490) and the Postgraduates' Innovation Program of Jiangsu Province (no. JX22013362).

\section{References}

[1] S. S. Rao, K. Rattanakovit, and T. Patcharatrakul, "Diagnosis and management of chronic constipation in adults," Nature Reviews Gastroenterology \& Hepatology, vol. 13, pp. 295-305, 2016.

[2] S. M. Mugie, M. A. Benninga, and C. Di Lorenzo, "Epidemiology of constipation in children and adults: a systematic review," Best Practice \& Research Clinical Gastroenterology, vol. 25, pp. 3-18, 2011.

[3] H. Chu, L. Zhong, H. Li, X. Zhang, J. Zhang, and X. Hou, "Epidemiology characteristics of constipation for general population, pediatric population, and elderly population in China," Gastroenterology Research and Practice, vol. 2014, Article ID 532734, 11 pages, 2014.

[4] A. E. Bharucha and S. S. Rao, "An update on anorectal disorders for gastroenterologists," Gastroenterology, vol. 146, pp. 37.e2-45.e2, 2014.

[5] E. Surrenti, D. M. Rath, J. H. Pemberton, and M. Camilleri, "Audit of constipation in a tertiary referral gastroenterology practice," The American Journal of Gastroenterology, vol. 90, pp. 1471-1475, 1995.

[6] S. S. Rao, A. K. Tuteja, T. Vellema, J. Kempf, and M. Stessman, "Dyssynergic defecation: demographics, symptoms, stool patterns, and quality of life," Journal of Clinical Gastroenterology, vol. 38, pp. 680-685, 2004.

[7] S. S. Rao, K. D. Welcher, and J. S. Leistikow, "Obstructive defecation: a failure of rectoanal coordination," The American Journal of Gastroenterology, vol. 93, pp. 1042-1050, 1998.

[8] A. C. Ford and N. C. Suares, "Effect of laxatives and pharmacological therapies in chronic idiopathic constipation: systematic review and meta-analysis," Gut, vol. 60, pp. 209-218, 2011.

[9] J. F. Johanson and J. Kralstein, "Chronic constipation: a survey of the patient perspective," Alimentary Pharmacology \& Therapeutics, vol. 25, pp. 599-608, 2007.

[10] P. Denis, "Methodology of biofeedback," European Journal of Gastroenterology \& Hepatology, vol. 8, pp. 530-533, 1996.

[11] A. V. Emmanuel and M. A. Kamm, "Response to a behavioural treatment, biofeedback, in constipated patients is associated with improved gut transit and autonomic innervation," Gut, vol. 49, pp. 214-219, 2001.
[12] G. Bleijenberg and H. C. Kuijpers, "Treatment of the spastic pelvic floor syndrome with biofeedback," Diseases of the Colon and Rectum, vol. 30, pp. 108-111, 1987.

[13] G. Chiarioni, W. E. Whitehead, V. Pezza, A. Morelli, and G. Bassotti, "Biofeedback is superior to laxatives for normal transit constipation due to pelvic floor dyssynergia," Gastroenterology, vol. 130, pp. 657-664, 2006.

[14] M. M. Ba-Bai-Ke-Re, N. R. Wen, Y. L. Hu et al., "Biofeedbackguided pelvic floor exercise therapy for obstructive defecation: an effective alternative," World Journal of Gastroenterology, vol. 20, pp. 9162-9169, 2014.

[15] S. L. Hart, J. W. Lee, J. Berian, T. R. Patterson, A. Del Rosario, and M. G. Varma, "A randomized controlled trial of anorectal biofeedback for constipation," International Journal of Colorectal Disease, vol. 27, pp. 459-466, 2012.

[16] A. E. Bharucha, J. H. Pemberton, and G. R. Locke 3rd, “American Gastroenterological Association technical review on constipation," Gastroenterology, vol. 144, pp. 218-238, 2013.

[17] G. Lindberg, S. S. Hamid, P. Malfertheiner et al., "World Gastroenterology Organisation global guideline: constipation-a global perspective," Journal of Clinical Gastroenterology, vol. 45, pp. 483-487, 2011.

[18] H. J. Lee, K. W. Jung, and S. J. Myung, "Technique of functional and motility test: how to perform biofeedback for constipation and fecal incontinence," Journal of Neurogastroenterology and Motility, vol. 19, pp. 532-537, 2013.

[19] S. M. Murad-Regadas, F. S. Regadas, C. C. Bezerra et al., "Use of biofeedback combined with diet for treatment of obstructed defecation associated with paradoxical puborectalis contraction (anismus): predictive factors and short-term outcome," Diseases of the Colon and Rectum, vol. 59, pp. 115-121, 2016.

[20] S. J. Lewis and K. W. Heaton, "Stool form scale as a useful guide to intestinal transit time," Scandinavian Journal of Gastroenterology, vol. 32, pp. 920-924, 1997.

[21] G. F. Longstreth, W. G. Thompson, W. D. Chey, L. A. Houghton, F. Mearin, and R. C. Spiller, "Functional bowel disorders," Gastroenterology, vol. 130, pp. 1480-1491, 2006.

[22] Y. R. Tang, W. W. Yang, M. L. Liang, X. Y. Xu, M. F. Wang, and L. Lin, "Age-related symptom and life quality changes in women with irritable bowel syndrome," World Journal of Gastroenterology, vol. 18, pp. 7175-7183, 2012.

[23] F. Agachan, T. Chen, J. Pfeifer, P. Reissman, and S. D. Wexner, "A constipation scoring system to simplify evaluation and management of constipated patients," Diseases of the Colon and Rectum, vol. 39, pp. 681-685, 1996.

[24] W. W. Zung, "A rating instrument for anxiety disorders," Psychosomatics, vol. 12, pp. 371-379, 1971.

[25] W. W. Zung, "A self-rating depression scale," Archives of General Psychiatry, vol. 12, pp. 63-70, 1965.

[26] R. An, L. Tian, M. Liu et al., "Application of the anxiety and depression scale of patients with nasal septum deviation," Lin Chung Er Bi Yan Hou Tou Jing Wai Ke Za Zhi, vol. 30, pp. 35-38, 2016.

[27] A. L. Stewart, R. D. Hays, and J. E. Ware Jr., "The MOS shortform general health survey. Reliability and validity in a patient population," Medical Care, vol. 26, pp. 724-735, 1988.

[28] D. J. Buysse, C. F. Reynolds 3rd, T. H. Monk, S. R. Berman, and D. J. Kupfer, "The Pittsburgh Sleep Quality Index: a new instrument for psychiatric practice and research," Psychiatry Research, vol. 28, pp. 193-213, 1989. 
[29] P. S. Tsai, S. Y. Wang, M. Y. Wang et al., "Psychometric evaluation of the Chinese version of the Pittsburgh Sleep Quality Index (CPSQI) in primary insomnia and control subjects," Quality of Life Research, vol. 14, pp. 1943-1952, 2005.

[30] O. Dedeli, I. Turan, R. Ozturk, and S. Bor, "Normative values of the balloon expulsion test in healthy adults," The Turkish Journal of Gastroenterology, vol. 18, pp. 177-181, 2007.

[31] M. Minguez, B. Herreros, V. Sanchiz et al., "Predictive value of the balloon expulsion test for excluding the diagnosis of pelvic floor dyssynergia in constipation," Gastroenterology, vol. 126, pp. 57-62, 2004.

[32] M. Y. Ke, R. Q. Li, and G. Z. Pan, "Gastrointestinal transit time measurement and its pathophysiological significance," Chinese Journal of Internal Medicine, vol. 29, pp. 721-724, 1990.

[33] Z. J. Wang and D. H. Yu, "The value of colonic transit test, diagnostic criteria and clinical application," Journal of Coloproctological Surgery, vol. 9, pp. 79-82, 2003.

[34] M. Sauter, H. Heinrich, M. Fox et al., “Toward more accurate measurements of anorectal motor and sensory function in routine clinical practice: validation of high-resolution anorectal manometry and rapid barostat bag measurements of rectal function," Neurogastroenterology and Motility, vol. 26, pp. 685-695, 2014.

[35] M. Ding, Z. Lin, L. Lin, H. Zhang, and M. Wang, "The effect of biofeedback training on patients with functional constipation," Gastroenterology Nursing, vol. 35, pp. 85-92, 2012.

[36] C. J. Liu, X. N. Li, X. H. Ren, J. Li, J. Zhang, and D. Sun, "Feasibility of using short form 36 in Chinese population," Journal of West China Universityof Medical Sclences, vol. 32, p. 39, 2001.

[37] D. Nellesen, A. Chawla, D. L. Oh, T. Weissman, B. J. Lavins, and C. W. Murray, "Comorbidities in patients with irritable bowel syndrome with constipation or chronic idiopathic constipation: a review of the literature from the past decade," Postgraduate Medicine, vol. 125, pp. 40-50, 2013.

[38] R. Mody, A. Guerin, B. Fok et al., "Prevalence and risk of developing comorbid conditions in patients with chronic constipation," Current Medical Research and Opinion, vol. 30, no. 12, pp. 2505-2513, 2014.

[39] S. Singh, S. Heady, E. Coss-Adame, and S. S. Rao, "Clinical utility of colonic manometry in slow transit constipation," Neurogastroenterology and Motility, vol. 25, pp. 487-495, 2013.

[40] U. Karlbom, L. Pahlman, S. Nilsson, and W. Graf, "Relationships between defecographic findings, rectal emptying, and colonic transit time in constipated patients," Gut, vol. 36, pp. 907-912, 1995.

[41] J. S. Soh, H. J. Lee, K. W. Jung et al., “The diagnostic value of a digital rectal examination compared with high-resolution anorectal manometry in patients with chronic constipation and fecal incontinence," The American Journal of Gastroenterology, vol. 110, pp. 1197-1204, 2015.

[42] F. Cadeddu, F. Salis, E. De Luca, I. Ciangola, and G. Milito, "Efficacy of biofeedback plus transanal stimulation in the management of pelvic floor dyssynergia: a randomized trial," Techniques in Coloproctology, vol. 19, pp. 333-338, 2015.

[43] S. S. Rao, J. Valestin, C. K. Brown, B. Zimmerman, and K. Schulze, "Long-term efficacy of biofeedback therapy for dyssynergic defecation: randomized controlled trial," The American Journal of Gastroenterology, vol. 105, pp. 890-896, 2010.
[44] J. Wang, M. H. Luo, Q. H. Qi, and Z. L. Dong, "Prospective study of biofeedback retraining in patients with chronic idiopathic functional constipation," World Journal of Gastroenterology, vol. 9, pp. 2109-2113, 2003.

[45] Z. A. Khan, C. Whittal, S. Mansol, L. A. Osborne, P. Reed, and S. Emery, "Effect of depression and anxiety on the success of pelvic floor muscle training for pelvic floor dysfunction," The Australian \& New Zealand Journal of Obstetrics \& Gynaecology, vol. 33, pp. 710-714, 2013.

[46] R. Lea, L. A. Houghton, E. L. Calvert et al., "Gut-focused hypnotherapy normalizes disordered rectal sensitivity in patients with irritable bowel syndrome," Alimentary Pharmacology \& Therapeutics, vol. 17, no. 5, pp. 635-642, 2003.

[47] L. S. Shim, M. Jones, G. M. Prott, L. I. Morris, J. E. Kellow, and A. Malcolm, "Predictors of outcome of anorectal biofeedback therapy in patients with constipation," Alimentary Pharmacology \& Therapeutics, vol. 33, pp. 1245-1251, 2011.

[48] S. Heymen, K. R. Jones, Y. Scarlett, and W. E. Whitehead, "Biofeedback treatment of constipation: a critical review," Diseases of the Colon and Rectum, vol. 46, pp. 1208-1217, 2003.

[49] H. Y. Tang, S. L. Sayers, G. Weissinger, and B. Riegel, "The role of depression in medication adherence among heart failure patients," Clinical Nursing Research, vol. 23, pp. 231244, 2014.

[50] O. Turan, B. Yemez, and O. Itil, "The effects of anxiety and depression symptoms on treatment adherence in COPD patients," Primary Health Care Research \& Development, vol. 15, pp. 244-251, 2014.

[51] C. H. Knowles and G. Farrugia, "Gastrointestinal neuromuscular pathology in chronic constipation," Best Practice \& Research Clinical Gastroenterology, vol. 25, pp. 43-57, 2011.

[52] W. R. Schouten, M. J. Gosselink, M. O. Boerma, and A. Z. Ginai, "Rectal wall contractility in response to an evoked urge to defecate in patients with obstructed defecation," Diseases of the Colon and Rectum, vol. 41, pp. 473-479, 1998.

[53] R. M. Mollen, B. Salvioli, M. Camilleri et al., "The effects of biofeedback on rectal sensation and distal colonic motility in patients with disorders of rectal evacuation: evidence of an inhibitory rectocolonic reflex in humans?," The American Journal of Gastroenterology, vol. 94, pp. 751-756, 1999.

[54] G. Chiarioni, L. Salandini, and W. E. Whitehead, "Biofeedback benefits only patients with outlet dysfunction, not patients with isolated slow transit constipation," Gastroenterology, vol. 129, pp. 86-97, 2005. 


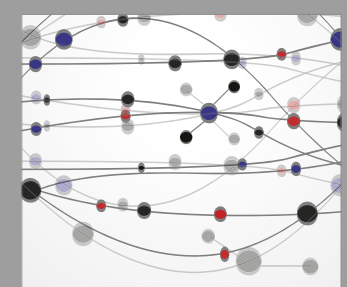

The Scientific World Journal
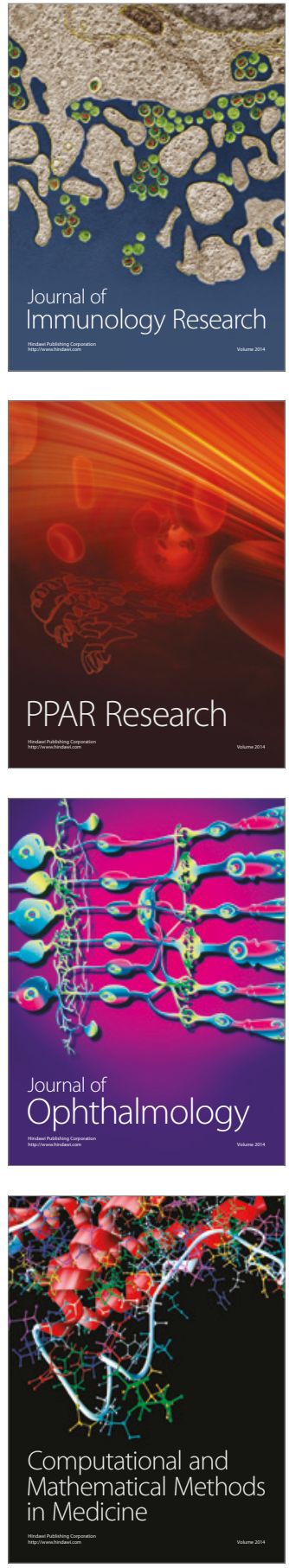

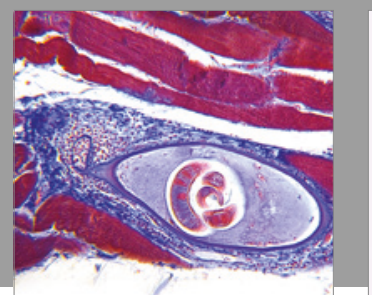

Gastroenterology Research and Practice
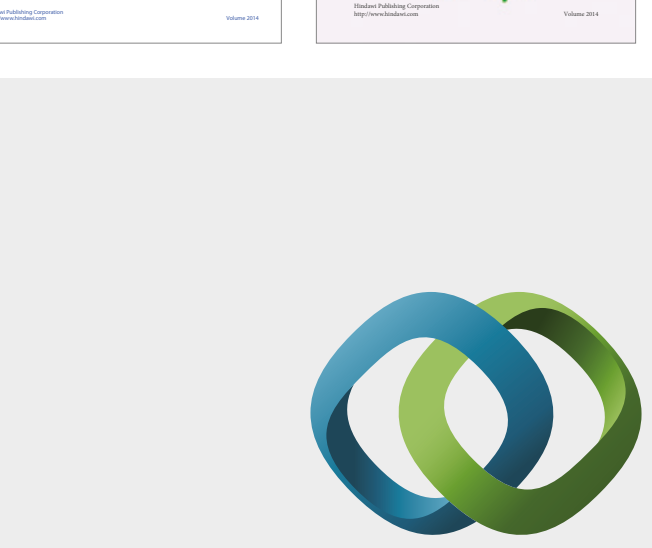

\section{Hindawi}

Submit your manuscripts at

https://www.hindawi.com
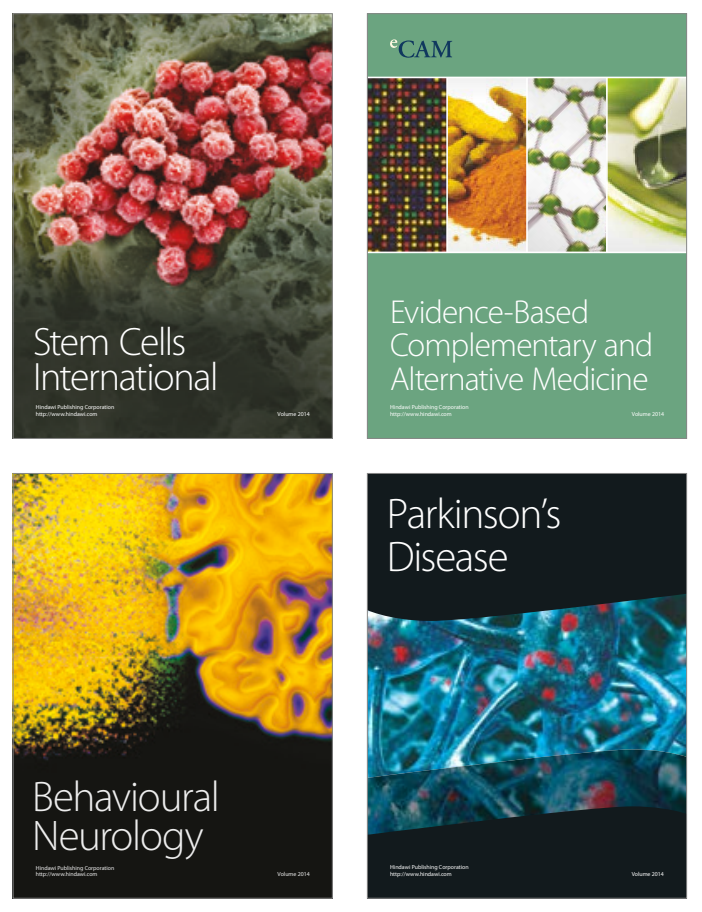
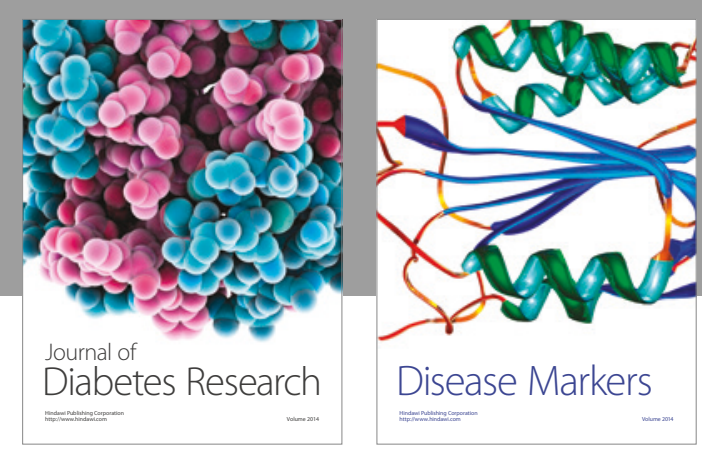

Disease Markers
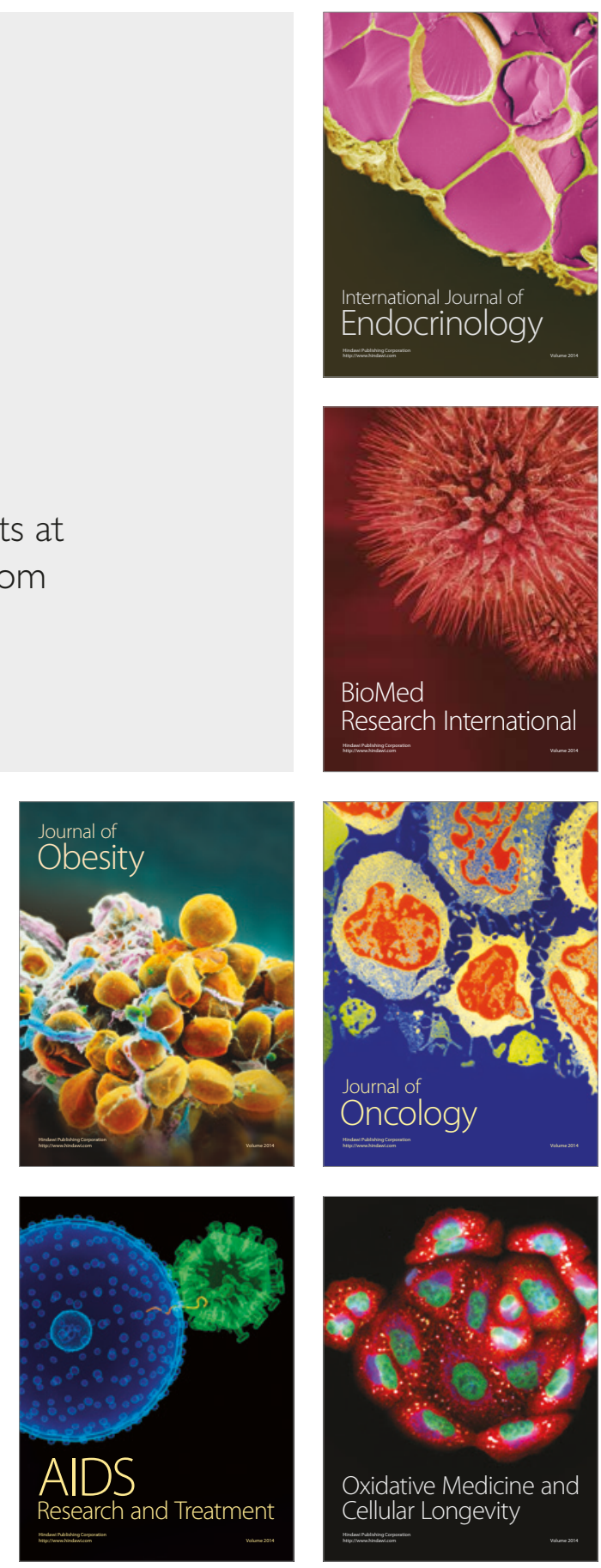